\title{
Strategi Penentuan Potensi Penghematan Energi Unit Heat Exchanger Kilang PPSDM Migas Menggunakan Analisis Metoda Pinch
}

\author{
Bambang Priandoko \\ Pusat Pengembangan Sumber Daya Manusia Energi Baru, Terbarukan \& Konservasi Energi, \\ Jakarta Timur
}

\section{INFORMASI NASKAH}

Diterima: 17 Februari 2021

Direvisi: 12 April 2021

Disetujui: 21 Juni 2021

Terbit: 22 Juni 2021

Email korespondensi:

Bambang.Priandoko@esdm.go.id, Bpriandoko0@gmail.com

Laman daring:

https://doi.org/10.37525/mz/2021$1 / 275$

\begin{abstract}
ABSTRAK
Dalam penelitian ini dikembangkan strategi penentuan potensi penghematan energi pada proses pengolahan minyak menggunakan metoda analisis pinch. Pada metoda analisis pinch ini didasarkan pada prinsip-prinsip thermodinamika dalam mengurangi pemakaian energi pada keseluruhan proses, baik itu memaksimalkan energi panas (heat recovery) yang dibutuhkan proses,maupun mengurangi panas pada proses tersebut. Analisis potensi penghematan energi dilakukan pada sistem Heat Exchanger proses pengolahan Kilang di PPSDM Migas Cepu. Pada Heat Exchanger tersebut dihasilkan Energi panas yang ditransfer produk ke crude oil sebesar 103.2 KW sedangkan berdasarkan analysis pinch, energi minimum yang harus dimiliki unit utliiti tersebut sebesar $248.58 \mathrm{KW}$ sehingga energi yang dapat dihemat sebesar $3490 \mathrm{KWh}$ per hari. Kemudian energi panas yang diterima crude oil sebesar $84 \mathrm{KW}$, berdasarkan analisis pinch energi maksimum yang harus dimiliki unit utiliti tersebut sebesar $36.38 \mathrm{KW}$ sehingga energi yang dapat dihemat sebesar $1142.88 \mathrm{KWh}$ per hari. Temperatur crude oil tersebut dapat ditingkatkan dari $95^{\circ} \mathrm{C}$ menjadi $104^{\circ} \mathrm{C}$ dan temperatur produk dapat diturunkan dari $145^{\circ} \mathrm{C}$ menjadi $124.2^{\circ} \mathrm{C}$.
\end{abstract}

Kata kunci: analisis pinch, crude oil, efisiensi energi, Heat Exchanger, residu

\section{ABSTRACT}

In the research, the Strategy to determine the potential for energy savings in oil processing was developed using the pinch analysis method. In this pinch analysis method is based on thermodynamic principles in reducing energy 
consumption in the whole process, either maximizing heat energy (heat recovery) required by the process, or reducing heat in the process. Analysis of the potential for energy savings was carried out on the Heat Exchanger system for the refinery processing process at PPSDM Migas Cepu. In the Heat Exchanger, heat energy is produced which is transferred to crude oil of $103.2 \mathrm{KW}$, while based on the pinch analysis, the minimum energy that the utility unit must have is 248.58 $K W$ so that the energy that can be saved is $3490 \mathrm{KWh}$ per day. Then the heat energy received by Crude Oil is $84 \mathrm{KW}$, based on the pinch analysis of the maximum energy that the utility unit must have is $36.38 \mathrm{KW}$ so that the energy that can be saved is $1142.88 \mathrm{KWh}$ per day. The temperature of the crude oil can be increased from $95^{\circ} \mathrm{C}$ to $104^{\circ} \mathrm{C}$ and the product temperature can be reduced from $145^{\circ} \mathrm{C}$ to 124. $2^{\circ} \mathrm{C}$.

Keywords: crude oil, energy

efficiency, heat exchanger, pinch

analysis, residue

\section{PENDAHULUAN}

Pengolahan crude oil kilang minyak di PPSDM Migas merupakan saran penunjang penunjang praktik peserta training maupun Politeknik PEM Akamigas dalam meningkatkan kemampuan kegiatan di lapangan. Selain itu hasil pengolahan minyak tersebut juga digunakan untuk membantu PT. Pertamina mengolah crude oil menjadi produk yang bermanfaat, seperti solar, berbagai jenis Pertasol serta residu bagi masyarakat. Jasa pengolahan minyak dari PT PERTAMINA tersebut digunakan PPSDM Migas sebagai peningkatan pelayanan Badan Layanan Umum (BLU) sehingga terjalin kerjasama yang saling menguntungkan kedua belah pihak. Untuk meningkatkan pelayanan tersebut, maka PPSDM Migas berusaha meningkatkan kemampuan kinerja kilang minyak tersebut. Peningkatkan kinerja atau efisiensi tersebut dapat dilakukan di satu unit kilang ataupun dari beberapa signifikan energi uses peralatan penunjang pengolahan minyak tersebut, seperti optmalisasi bahan bakar, peningkatan kinerja unit utilities, unit Heat Exchanger dan lain-lain.

Proses Pengolahan crude oil di PPSDM Migas dilaksanakan dengan sistem pemisahan yang terjadi pada Crude Distillation Unit (CDU). Proses ini terjadi di Distilasi Atmosferik. Unit distilasi atmosferik adalah suatu unit yang bertugas melaksanakan seluruh rangkaian kegiatan pemisahan crude oil menjadi produk-produk minyak bumi berdasarkan trayek titik didihnya pada tekanan satu atmosfir.

Kilang PPSDM MIGAS mengolah campuran crude oil dari lapangan Kawengan dan Ledok milik PT. Pertamina EP Aset 4 Field Cepu. Adapun karakteristik crude oil dari lapangan Kawengan merupakan minyak HPPO (High Pour Point Oil) bersifat parafinis, yaitu mengandung lilin, alkana rantai lurus dan nilai oktan rendah. Sedangkan crude oil dari Lapangan Ledok bersifat aspaltis, yaitu mengandung Aspal, struktur rantai tertutup, nilai oktan tinggi. Crude oil Ledok sering disebut minyak LPPO (Light Pour Point Oil). Produk utama dari pengolahan crude oil di PPSDM Migas saat ini adalah Pertasol CA, Pertasol CB, Pertasol CC, Solar dan Residu. Dalam melaksanakan operasinya, Kilang PPSDM MIGAS didukung oleh fasilitas utilitas. Salah satu indikator efisiensi energi di pengolahan minyak adalah efisiensi penggunaan bahan bakar di Furnace CDU. Bahan bakar yang digunakan di unit CDU PPSDM Migas Cepu adalah fuel oil dan Fuel gas yang diperoleh dari sisa pengolahan CDU. Semakin tinggi temperatur bahan bakar yang digunakan makan akan semakin efisien. 
Begitu juga semakin tinggi temperatur umpan yang dikirim ke CDU akan semakin efisien kinerja furnace tersebut

Pada makalah ini dikembangkan analisis potensi penghematan energi yang terjadi di unit Heat Exchanger (HE) menggunakan analisis metoda pinch. Panas yang dihasilkan dari produk bawah melalui HE1, HE2, HE3, HE4 dan HE5 harus sekecil mungkin kehilangan energi panas proses destilasi tersebut, sehingga energi panas yang digunakan maksimal pada pemanasan crude oil melalui HE1, HE2, HE3, HE4 dan HE5, seperti yang diperlihatkan pada gambar 1 berikut:

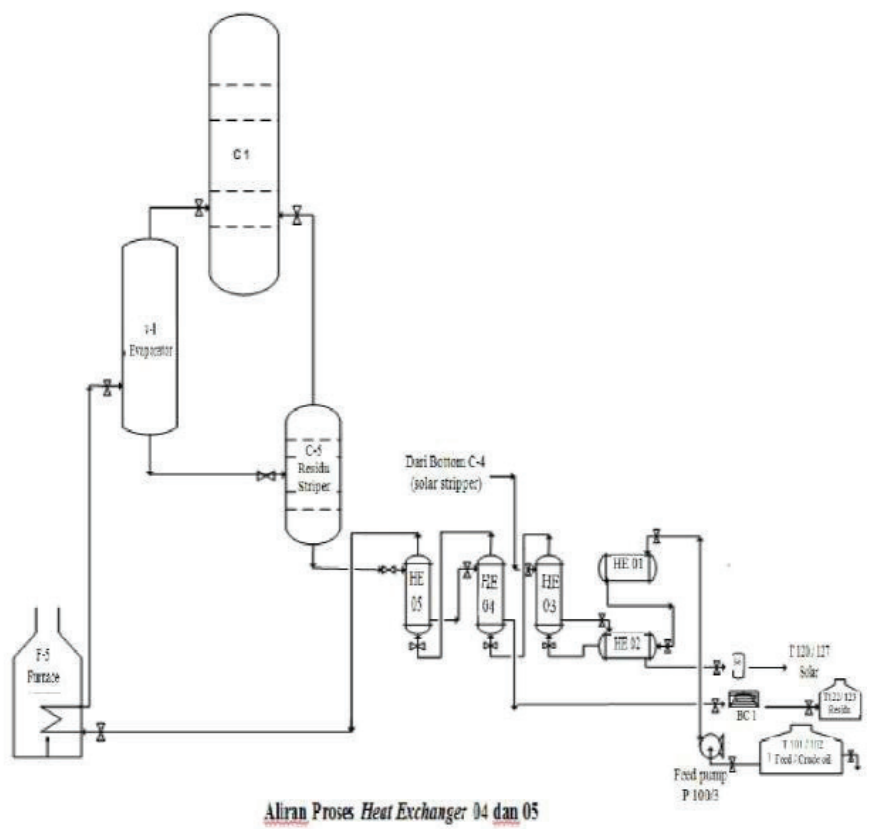

Gambar 1: Aliran Proses Heat Exchanger $04 \& 05$

Berdasarkan pada gambar 1 tersebut energi panas yang diterima crude oil terserap seluruhnya dan energi panas produk yang diberikan ke crude oil maksimal sehingga optimalisasi bahan bakar terjadi di unit Furnace kilang tersebut.

\section{METODE PENELITIAN}

Pinch analysis awalnya merupakan teknik yg dikembangkan untuk mendapatkan gambaran menyeluruh (overview) mengenai kebutuhan energi untuk pendinginan (cooling utility), pemanasan (heating utility), dan berapa jumlah energi yg bisa digunakan (energy recovery) di antara aliran-aliran proses yang ada. Pada makalah ini, tahapan-tahapan penelitian ini adalah

1. Melakukan pengambilan data temperature HE1, HE2, HE3, HE4 dan HE5 baik pendinginn produk maupun pemanasan crude oil.

2. Menentukan nilai Entalphi dari setiap proses menggunakan aplikasi software RefPro.

3. Menggambarkan hubungan temperatur dan entalphi dari hot stream yang menurunkan temperatur dan cold stream yang menaikkan temperature.

4. Membuat kurva Composite merupakan representasi dari keseluruhan aliran proses hot (hot composite curve) atau cold (cold composite curve)

5. Menentukan terlebih dahulu berapa perbedaan temperatur yg diperbolehkan sbg batas minimum untuk transfer energi. Beda temperature yang digunakan dalam penelitian ini sebesar $10^{\circ} \mathrm{C}$.

6. Menurunkan Data temperatur hot streams sebesar $10^{\circ} \mathrm{C} / 2=5^{\circ} \mathrm{C}$, dan data temperatur cold streams dinaikkan juga sebesar $5^{\circ} \mathrm{C}$. Hal ini dilakukan untuk mendekatkan kedua kurva di atas sehingga saling bersentuhan.

Setelah ditentukan pinch point hot stream dan cold stream maka perancangan HE dilakukan dengan menggunakan persamaan energi :

$\mathrm{Q}_{\text {hot stream }}=\mathrm{Q}_{\text {cold stream }}=\mathrm{m} * \mathrm{C}_{\mathrm{p}} * \mathrm{dT}$

Q : Energi panas, Kilo Watt (KW)

$\mathrm{m} \quad$ : massa fluida (crude oil atau produk) (Kg)

$\mathrm{C}_{\mathrm{p}}$ : spesifik panas fluida $\left(\mathrm{KW} / \mathrm{Kg}^{0} \mathrm{C}\right)$

dT $\quad$ : beda temperature masuk $\left(\mathrm{T}_{\mathrm{in}}\right)$ dengan temperatur keluar $\left(\mathrm{T}_{\text {out }}\right)$. 
$\mathrm{Q}_{\text {hot stream }}$ : turunnya energi panas

$\mathrm{Q}_{\text {cold stream }}$ : Naikknya Energi Panas

ada tiga aturan penting yang menyangkut heat exchanger antara hot dan cold stream sebagai berikut:

\section{A. Daerah di atas pinch point (above pinch)}

Untuk HE berada di atas pinch point, maka titik awal cold stream dan titik akhir hot stream sudah terpaku pada pinch point dan terpisah sebesar beda temperatur minimum yang telah ditentukan sebelumnya.

dari pinch point ke daerah di atas pinch, titik awal cold stream dan titik akhir hot stream sudah terpatok untuk terpisah sebesar beda tempertur minimum yang telah tentukan sebelumnya.

\section{B. Daerah di bawah pinch point (below pinch)}

Hal yg sebaliknya berlaku di daerah pinch point. Titik awal hot stream dan titik akhir cold stream sudah terpaku pada pinch point dan terpisah sebesar $10^{\circ} \mathrm{C}$. Untuk menghindari temperature cross, kapasitas energi hot stream harus lebih besar atau minimal sama dengan kapasitas energi cold stream, atau $\left(\mathrm{m}^{*} \mathrm{Cp}\right)^{\mathrm{H}} \geq$ $\left(\mathrm{m}^{*} \mathrm{Cp}\right)^{\mathrm{C}}$.

\section{Tidak ada pertukaran panas (heat exchange) melewati pinch point}

Untuk memaksimalkan heat recovery dan meminimalkan utilities, tidak dibenarkan melakukan heat exchange yg melewati pinch point. Heat exchange di daerah atas pinch hanya boleh dilakukan oleh hot dan cold streams yang ada di daerah tersebut, beserta hot utilities. Sementara heat exchanger di daerah bawah pinch hanya boleh dilakukan oleh hot dan cold streams di daerah tersebut dan cold utilities.

\section{HASIL PENELITIAN DAN PEMBAHA-} SAN

Pada penelitian ini, analisis pinch dilakukan pada proses sistem pertukaran panas (Heat Echanger) antara produk bawah kolom distilasi dengan crude oil pada kilang PPSDM Migas Cepu. Massa total crude oil yang digunakan sebesar $298.8 \mathrm{~m}^{3} /$ hari setara dengan 296.65 Ton/hari, serta residu sisa hasil olahan CDU yang dugunakan untuk bahan bakar kurang lebih 4\% per hari.

Hasil yang diperoleh adalah memaksimum heat recovery produk yang ditransfer ke crude oil pada sistem Heat Exchanger tersebut, seperti yang dipelihatkan pada gambar 1. Pada gambar 1 tersebut Hot stream dan Cold stream sistem Heat Exchanger kemudian dibuatkan dalam bentuk tabel 1 berikut:

Tabel 1: Cold stream $(\mathrm{H})$

\begin{tabular}{|c|c|c|c|c|}
\hline $\begin{array}{c}\text { Cold } \\
\text { Stream }\end{array}$ & $\begin{array}{c}\text { Delta } \mathrm{H} \\
(\mathrm{KW})\end{array}$ & $\begin{array}{c}\mathrm{T}_{\text {in }} \\
\left({ }^{\circ} \mathrm{C}\right)\end{array}$ & $\begin{array}{c}\mathrm{T}_{\text {out }} \\
\left({ }^{\circ} \mathrm{C}\right)\end{array}$ & $\begin{array}{c}\text { Crude } \\
\text { Oil }\end{array}$ \\
\hline $\mathrm{C} 1$ & 84.1 & 75 & 95 & HE04 \\
\hline $\mathrm{C} 2$ & 50.5 & 95 & 112 & HE05 \\
\hline
\end{tabular}

Tabel 2: Hot Stream

\begin{tabular}{|c|c|c|c|c|}
\hline $\begin{array}{c}\text { Hot } \\
\text { Stream }\end{array}$ & $\begin{array}{c}\mathrm{F} \mathrm{CV} \\
(\mathrm{KW})\end{array}$ & $\begin{array}{c}\mathrm{T}_{\text {in }} \\
\left({ }^{\circ} \mathrm{C}\right)\end{array}$ & $\begin{array}{c}\mathrm{T}_{\text {out }} \\
\left({ }^{\circ} \mathrm{C}\right)\end{array}$ & Residu \\
\hline $\mathrm{H} 1$ & 195.8 & 250 & 145 & HE05 \\
\hline $\mathrm{H} 2$ & 126 & 145 & 114 & HE04 \\
\hline
\end{tabular}

Besarnya entalphi diperoleh dengan cara memasukkan unsur-unsur dari produk dan crude oil kedalam aplikasi software RefProp kemudian dibuatkan bentuk grafik antara temperatur dan entalphi dari fluida tersebut, sehingga entalphi diperoleh seperti yang diperlihatkan pada gambar 2 berikut 


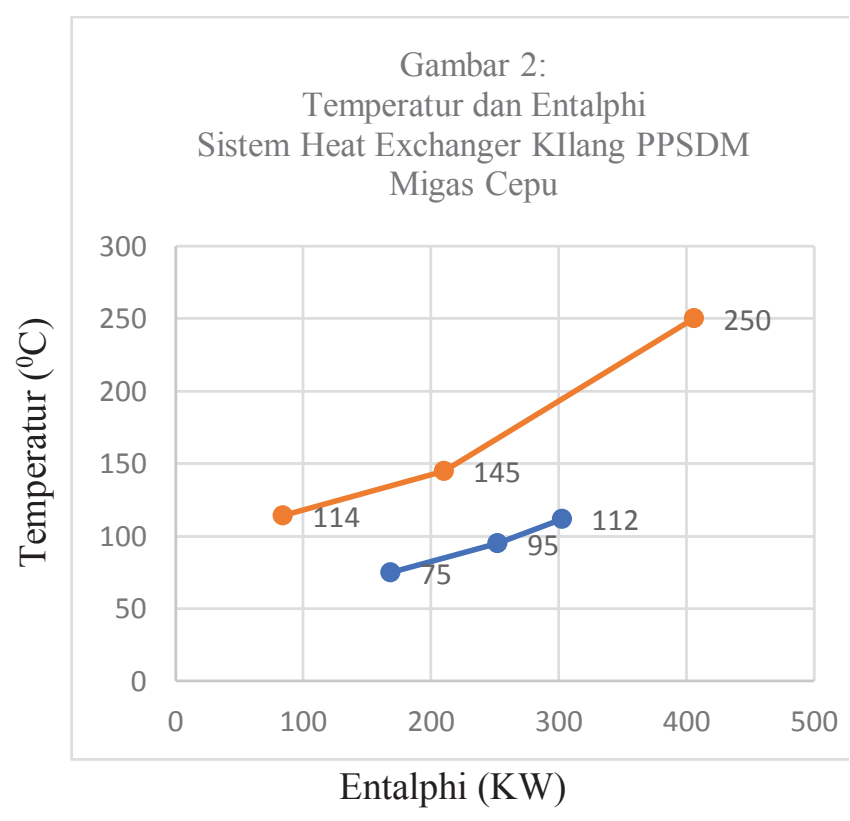

Grafik pada gambar 2 tersebut merupakan gambaran kondisi real proses, adapun hasil prediksi berdasrkan analisis pinch menggunakan delta minimum $10^{\circ} \mathrm{C}$ [I.C. Kemp, 2007] seperti diperlihatkan pada gambar 3 berikut :

Gambar 3 : Temperatur dan Entalphi delta $\mathrm{T}=10^{\circ} \mathrm{C}$

Sistem Heat Exchanger PPSDM Migas

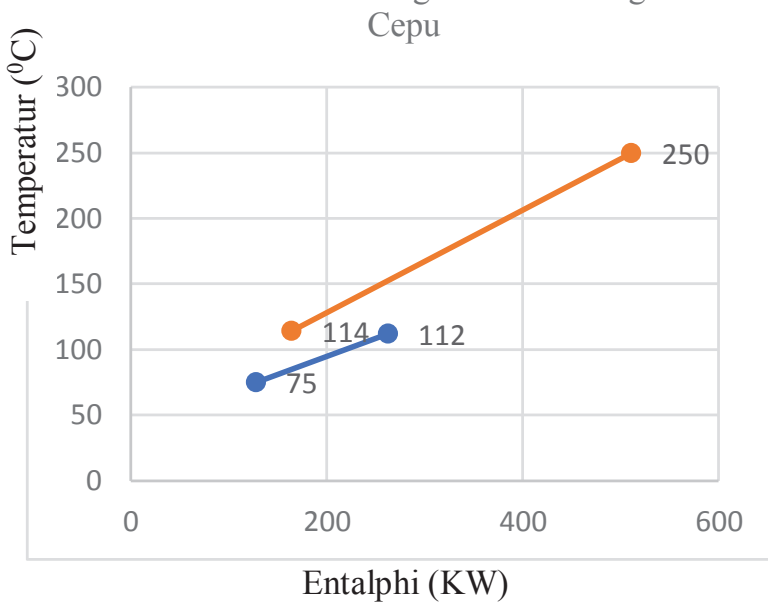

Berdasarkan tabel dan gambar 2 tersebut kemudian dibuat keseluruhan aliran proses hot composite dan cold composite, seperti yang dipelihatkan pada gambar 4 berikut:

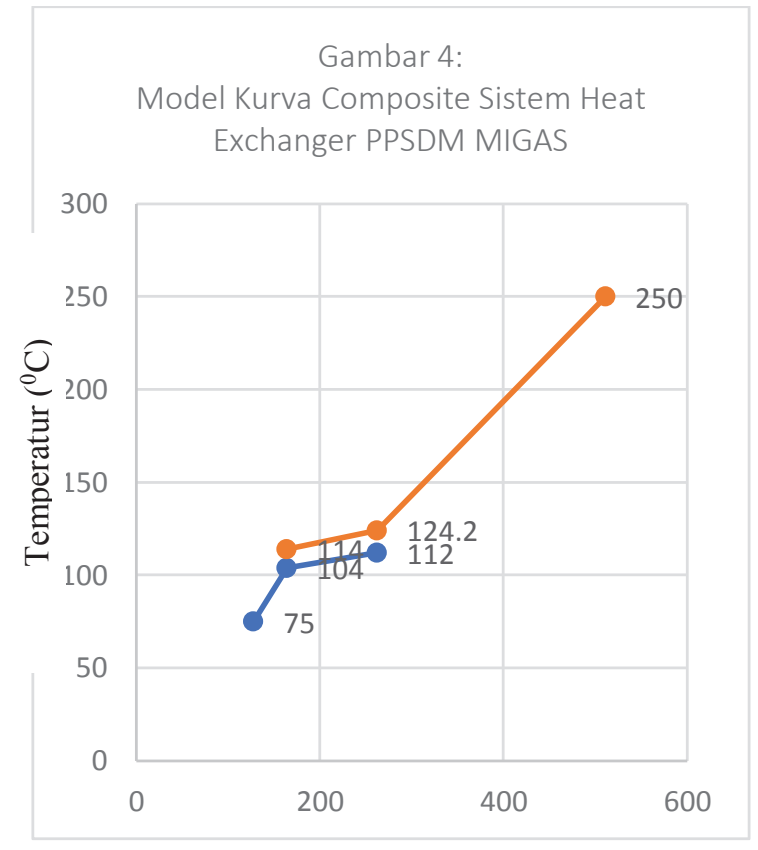

Entalphi (KW)

Beda temperatur yang dipebolehkan sebagai batas minimum untuk transfer energi adalah $10^{\circ} \mathrm{C}$. Kurva pada gambar 3 tersebut memperlihatkan kebutuhan energi keseluruhan aliran proses tersebut diperlihatkan pada tabel berikut:

Tabel 3 : Hasil Analisis Pinch Cold Stream

\begin{tabular}{|c|c|c|c|c|}
\hline $\begin{array}{c}\text { Cold } \\
\text { Stream }\end{array}$ & $\begin{array}{c}\text { Delta H } \\
\mathrm{KW})\end{array}$ & $\begin{array}{c}\mathrm{T}_{\text {in }} \\
\left({ }^{\circ} \mathrm{C}\right)\end{array}$ & $\begin{array}{c}\mathrm{T}_{\text {out }} \\
\left({ }^{\circ} \mathrm{C}\right)\end{array}$ & $\begin{array}{c}\text { Crude } \\
\text { Oil }\end{array}$ \\
\hline $\mathrm{C} 1$ & 34.38 & 75 & 95 & HE04 \\
\hline $\mathrm{C} 2$ & 252.3 & 104 & 112 & HE05 \\
\hline
\end{tabular}

Tabel 4: Hasil Analisis Pinch Hot Stream

\begin{tabular}{|c|c|c|c|c|}
\hline $\begin{array}{c}\text { Hot } \\
\text { Stream }\end{array}$ & $\begin{array}{c}\text { Delta H } \\
(\mathrm{KW})\end{array}$ & $\begin{array}{c}\mathrm{T} \text { in } \\
\left({ }^{\circ} \mathrm{C}\right)\end{array}$ & $\begin{array}{c}\text { Tout } \\
\left({ }^{\circ} \mathrm{C}\right)\end{array}$ & $\begin{array}{c}\text { Crude } \\
\text { Oil }\end{array}$ \\
\hline H1 & 248.58 & 250 & 124.2 & HE04 \\
\hline H2 & 98.22 & 124.2 & 114 & HE05 \\
\hline
\end{tabular}

Energi yang dapat direcovery dibawah titik pinch sebesar energi $248.58 \mathrm{KW}$ dari energi sebesar 103.2 KW dan energi yang dapat direcovery di atas titik pinch sebesar 
$3490 \mathrm{KWh}$ per hari. Kemudian energi panas yang diterima crude Oil sebesar $84 \mathrm{KW}$, berdasarkan analisis pinch energi maksimum yang harus dimiliki unit utiliti tersebut sebesar $36.38 \mathrm{KW}$ sehingga energi yang dapat dihemat sebesar $1142.88 \mathrm{KWh}$ per hari. Temperatur crude oil tersebut dapat ditingkatkan dari $95^{\circ} \mathrm{C}$ menjadi $104^{\circ} \mathrm{C}$ dan temperatur produk dapat diturunkan dari $145^{\circ} \mathrm{C}$ menjadi $124.2^{\circ} \mathrm{C}$.

\section{KESIMPULAN}

1. Pada Heat Exchanger Kilang PPSDM Migas Cepu, energi panas yang ditransfer produk ke crude oil sebesar 103.2 KW berdasarkan analysis pinch energi minimum yang harus dimiliki unit utliiti tersebut sebesar $248.58 \mathrm{KW}$ sehingga energi yang dapat dihemat sebesar 3490 KWh per hari

2. Energi panas yang diterima crude oil pada Heat Exchanger Kilang PPSDM Migas Cepu sebesar $84 \mathrm{KW}$, berdasarkan analisis pinch energi maksimum yang harus dimiliki unit utiliti tersebut sebesar 36.38 KW sehingga energi yang dapat dihemat sebesar 1142.88 KWh per hari.

3. Temperatur crude oil tersebut dapat ditingkatkan dari $95^{\circ} \mathrm{C}$ menjadi $104^{\circ} \mathrm{C}$ dan temperatur produk dapat diturunkan dari $145^{\circ} \mathrm{C}$ menjadi $124.2^{\circ} \mathrm{C}$.

\section{DAFTAR PUSTAKA}

Moran, M.J., Shapiro, H.N., 2006. Fundamentals of Engineering Thermodynamics, 3rd ed., John Wiley \& Sons, Hoboken, New Jersey, USA

Kotas, T.J., 1985. The Exergy Method of Thermal Plant Analysis, Butterworths, Essex, UK.

Ejan, A., 1996. Advanced Engineering Thermodynamics (2nd edition), Wiley, New York, USA
Cengel, A.Y., Boles, M.A., 2006. Thermodynamics Engineering Approach, Fifth Edition, McGraw Hill Companies, New York, USA

I. C. Kemp, 2007. Pinch Analysis and Process Integration : A User Guide on Process Integration for The Efficient Use of Energy. Amsterdam: Butterworth-Heinemann. 